\title{
White-tailed deer vary offspring sex-ratio according to maternal condition and age
}

\author{
Russell. L. Burke* and James M. Birch \\ Museum of Zoology and Department of Biology, University of Michigan, Ann Arbor, MI 48109- \\ 1079, USA
}

\begin{abstract}
We tested two models of adaptive offspring sex-ratio that predict opposite optimal reproductive strategies for female white-tail deer (Odocoileus virginianus). Trivers and Willard's model predicts that does (females) in particularly good condition should produce sons, and Williams refined their model to make specific predictions about optimal offspring number/sex choices. Verme's model results in very different predictions because of very different assumptions about which sex of offspring can best benefit from high levels of maternal resources. We found clear support for the Trivers and Willard/Williarns model when we analyzed data from road-killed does, and we furthermore question several of the assumptions of the Verme model.
\end{abstract}

Key words: adaptation; optimality model; reproduction.

\section{INTRODUCTION}

Trivers and Willard (1973) proposed that the optimal reproductive strategy for a mother is to produce offspring of the sex that can most benefit from the level of resources she can provide. They hypothesized that for species with significant sexual dimorphism biased toward larger males, females with above-average levels of resources would optimize reproductive success by producing relatively more sons, while mothers with below-average resources would do so by producing more daughters (reproductive success measured as number of grandchildren.) This hypothesis is based on the assumption that sons benefit most from the mother's better condition because her extra resources could be transferred into larger body size at weaning and a competitive advantage in future male-male interactions (Fig. 1a). To facilitate tests of their model, Trivers and Willard (1973) suggested several indices that might indicate a mother's available resource level, including litter size, maternal age, parity, body condition and social status.

*Present address: School of Natural Resources and Environment, University of Michigan, Ann Arbor, MI, 48109-1115, USA.rborke@umich.edu.

Received 18 January 1995.

Accepted 1 June 1995.
Williams (1979) elaborated on the Trivers and Willard model by predicting a specific pattern of offspring number and sex for species that produce one, two or three offspring. He stated that these patterns "should be predictable from assessments of maternal age, physiology, and proprietary resources". Williams assumed that the resources required to produce a single son were greater than those required to produce a single daughter, but less than those required to produce two daughters. Therefore, if mothers were arranged in order of increasing ability to invest in reproduction, their offspring number/sex classes would be as follows: no offspring; single daughter; single son; two daughters; one saon + one daughter; two sons; two daughters + one son etc. (Williams 1979).

Cervids are likely to fit the assumptions of this model because males provide little or no parental investment and therefore probably have much higher variation in reproductive success than do females (Clutton-Brock 1987). Also, sexual dimorphism can be extreme; for example, male whitetailed deer (Odocoileus virginianus Zimmermann 1780) are larger than females of the same age and, when fully grown, males' body mass is approximately twice that of females' (Leberg et al. 1991). In addition, litters of one or two (rarely three) offspring are common.

Verme (1983) presented an alternative hypothesis 

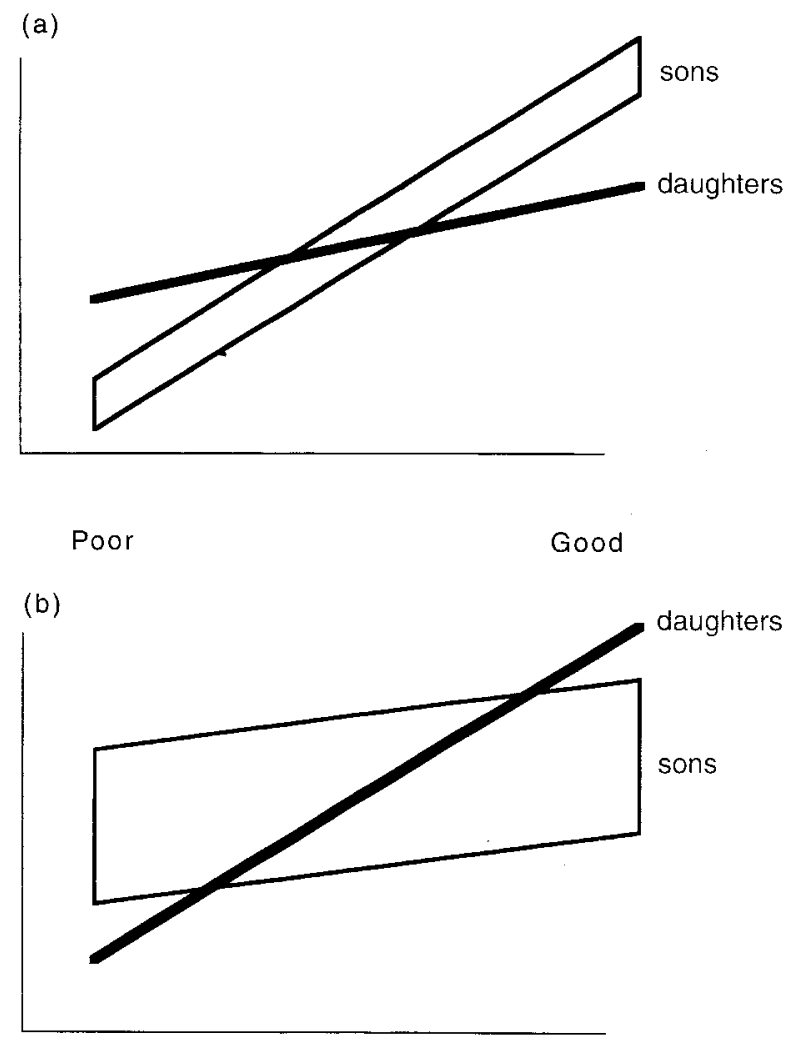

Mother's condition

Fig. 1. Qualitative comparison of relationships implictly assumed for the (a) Trivers and Willard (1973) and (b) Verme (1983) models. Note the larger variation in reproductive success associated with sons in (b), and the reversal of the fitness relationship associated with offspring sex between the models. Because of these differences in levels of variation, mothers in (a) have a much more important influence on their sons' future reproductive success than in (b).

in which dominant 0 . virginianus females (which tended to be in older age classes) were able to control a limited resource: quality fawning sites. These mothers would pass control of these sites on to their daughters, but not to their sons, which disperse from the local herd. This model was further developed by DeGayner and Jordan (1987), who suggested that while male reproductive success probably varies more than female reproductive success, the additional resources that a high condition doe can provide (inheritance of a high quality fawning site) has considerably less effect on a son's reproductive success than on a daughter's (Fig. 1b). They proposed that the high variation in male reproductive success is a result of conditions encountered after dispersal, and is not influenced by maternal investment. Support for this interpretation comes from their findings that older white-tailed deer does with twins had significantly more female offspring than did younger does with twins, and that maternal mass had no significant relationship with offspring sex. Thus, for Odocoileus, they questioned some of Trivers and Willard's assumptions: that a mother's high condition is translated into a particularly high quality son by the end of parental care, and/or that such a high quality son is likely to have a particularly high reproductive success.

It is important to note that the work of Verme (1965, 1969, 1983, 1985), Robinette et al. (1973) and McCullough (1979) are regularly cited as demonstrating that female Odocoileus do not skew sex ratio as predicted by the Trivers and Willard model. However, as pointed out by McCullough (1979) these investigators were specifically examining how 'herds' of deer responded to changes in resource levels (feeding level, range quality or density), not how individuals within those herds responded. They therefore reported population effects, rather than how individuals within those populations, which presumably placed themselves within a social hierarchy, may have skewed their offspring sex ratios (see Frank 1990). Thus, these data from Verme $(1965,1969,1983,1985)$, Robinette et al. (1973) and McCullough (1979) are not directly relevant to tests of either the Trivers and Willard or Verme models of how "individuals" may skew their offspring sex ratio.

In order to further test these two models, we examined a data set similar in size and collection method to that used by DeGayner and Jordan (1987). We analyzed the relationship of two indices of maternal condition with offspring sex: maternal age and mandibular fat. Maternal age has an uncertain relationship with reproductive fitness in Odocoileus. However, Williams (1979) suggested that for mammals in general, reproductive fitness may rise with age to a peak and then gradually drop off. Mandibular fat is commonly used by wildlife biologists as a measure of health and condition, particularly in relation to food availability (Kirkpatrick 1980; Verme \& Ulrey 1984). Furthermore, food availability has been shown to affect litter size, fetal weight and fetal development rate in 0 . virginianus (Verme 1963), and low food availability 
apparently reduces offspring sex ratio (i.e. fewer sons) in O. bemionus (Kucera 1991).

Our study, as for DeGayner \& Jordan (1987) and Kucera (1991), is distinctly different from the population studies cited above because we analyzed offspring sex ratios from individual does based on their own maternal condition and age. It is not based on herd condition generalized from measures of resource availability.

\section{METHODS}

We analyzed data on Michigan 0 . virginianus, most of which were road kills, collected between March and May 1986-88 (132 from 1986, 140 from 1987 and 415 from 1988). Fetus number and sex was determined in the field, and the lower mandibles were collected by the Michigan Department of Natural Resources (MDNR). Mandibles were used by the MDNR to determine age (based on tooth wear) and mandibular fat content, using standard techniques (e.g. Sauer 1984; Verme \& Ulrey 1984). Other, possibly more sensitive measures of condition (e.g. fat measures from other parts of the anatomy), were not recorded by MDNR personnel.

All statistical procedures were carried out using Systat version 5.01 (Wilkinson 1990). For each year's data, we grouped does for analysis according to the number and sex of their fetuses, and then ordered the groups as suggested by Williams (1979; e.g. no offspring, 1 daughter, 1 son, 2 daughters, 1 son and 1 daughter, 2 sons etc.; Tables 1-3). Groups containing fewer than three does were excluded from further analyses. We then tested each year's grouped data separately for increasing maternal age and increasing mandibular fat. We used the Lilliefors test (Wilkinson 1990) to determine which variables in each of the three data sets were normally distributed. Where variables were not normally distributed, we used logarithmic transformation and tested again for normal distribution. Where logarithmic transformation did not result in normal distribution, we used non-parametric tests only (see below).

Normally distributed data were further tested to assure that they fitted the assumptions of Model I ANOVA. Homogeneity of variance was tested using Bartlett's test (Wilkinson 1990). We assumed that
Table 1. Summary of 1986 mandibular condition and maternal age data, sorted by offspring number/sex class as suggested by Williams (1979)

\begin{tabular}{lrcc}
\hline & \multicolumn{2}{c}{ Mandibular fat (\%) } & $\begin{array}{c}\text { Maternal age (year) } \\
\text { mean (SD) }\end{array}$ \\
\hline No offspring & 56 & $22.6(20.5)$ & $2.1(3.0)$ \\
One daughter & 9 & $45.8(17.2)$ & $2.3(0.9)$ \\
One son & 10 & $43.2(25.9)$ & $3.1(2.0)$ \\
Two daughters & 13 & $42.2(17.8)$ & $6.3(2.9)$ \\
$\begin{array}{l}\text { One daughter, } \\
\quad 31\end{array}$ & $47.1(16.0)$ & $4.3(2.7)$ \\
$\quad$ one son & 13 & $45.2(21.5)$ & $4.7(3.0)$ \\
Two sons & 1 & 59.3 & 3.0 \\
Two daughters, & & & 12.0 \\
$\quad$ The son & 1 & 65.3 & \\
\hline
\end{tabular}

Table 2. Summary of 1987 mandibular conditions and maternal age data, sorted by offspring number/sex class as suggested by Williams (1979)

\begin{tabular}{|c|c|c|c|}
\hline & \multicolumn{2}{|c|}{ Mandibular fat $(\%)$} & \multirow{2}{*}{$\begin{array}{c}\text { Maternal age (year) } \\
\text { mean (SD) }\end{array}$} \\
\hline & $n$ & mean (SD) & \\
\hline No offspring & 56 & $41.6(17.1)$ & $1.5(1.7)$ \\
\hline One daughter & 11 & $59.1(13.5)$ & $3.0(2.4)$ \\
\hline One son & 15 & $51.6(17.9)$ & $3.6(2.6)$ \\
\hline Two daughters & 12 & $52.9(24.3)$ & $5.8(3.8)$ \\
\hline $\begin{array}{l}\text { One daughter, } \\
\text { one son }\end{array}$ & 28 & $54.1(18.4)$ & $4.0(1.6)$ \\
\hline Two sons & 19 & $54.6(14.2)$ & $3.7(1.7)$ \\
\hline Three daughters & 1 & 35.3 & 3.0 \\
\hline $\begin{array}{l}\text { Two daughters, } \\
\text { one son }\end{array}$ & 1 & 62.2 & 4.0 \\
\hline $\begin{array}{l}\text { One daughter, } \\
\text { two sons }\end{array}$ & 3 & $48.2(18.4)$ & $6.0(3.5)$ \\
\hline
\end{tabular}

measurement errors were independent and that they came from the same random, normal distribution with constant variance. We tested these assumptions by visual examinaion of probability plots of the residuals and plots of the Studentized residuals against estimated values. We also examined the normality of the residuals using skewness and kurtosis coefficients, and the Lilliefors test. Violations of these assumptions are noted below.

Maternal jaw fat and maternal age were analyzed separately for each year's data. We analyzed nor- 
Table 3. Summary of 1988 mandibular conditions and maternal age data, sorted by offspring number/sex class as suggested by Williams (1979).

\begin{tabular}{lccc}
\hline & \multicolumn{2}{c}{$\begin{array}{c}\text { Mandibular fat (\%) } \\
n\end{array}$} & $\begin{array}{c}\text { Maternal age (year) } \\
\text { mean (SD) }\end{array}$ \\
\hline No offspring & 125 & $38.2(22.4)$ & $1.1(0.5)$ \\
$\begin{array}{l}\text { One daughter } \\
\text { One son }\end{array}$ & 45 & $52.9(16.2)$ & $2.2(1.8)$ \\
Two daughters & 43 & $54.2(13.6)$ & $2.3(2.1)$ \\
$\begin{array}{l}\text { One daughter, } \\
\quad \text { one son }\end{array}$ & 88 & $52.3(18.3)$ & $3.5(2.1)$ \\
$\begin{array}{l}\text { Two sons } \\
\text { Three daughters }\end{array}$ & 1 & 64.0 & $3.3(1.9)$ \\
$\begin{array}{l}\text { Two daughters, } \\
\quad 10\end{array}$ & $62.7(6.6)$ & 3.0 \\
$\quad \begin{array}{l}\text { One son } \\
\text { One daughter, } \\
\text { two sons }\end{array}$ & 11 & $58.0(8.0)$ & $3.4(1.1)$ \\
Three sons & 5 & $58.8(6.3)$ & $3.0(1.0)$ \\
\hline
\end{tabular}

mally distributed data using a combination of one-way ANOVA and Spearman's rank correlation in an "ordered heterogeneity" (OH) test (Rice \& Gaines 1994a,b), which essentially results in a one-tailed ANOVA. Using the $\mathrm{OH}$ procedure it is possible to not only test whether a set of means differ from each other, as a standard ANOVA does, but to further test whether they differ in a particular order predicted by a hypothesis.

To begin the $\mathrm{OH}$ procedure, we performed standard ANOva, which resulted in a $P$ value useful for comparing the hypothesis $\mathrm{H}_{0}$ (that all means are equal) with the hypothesis $\mathrm{H}_{\mathrm{A}}$ (that at least one mean is not equal to at least one of the others). We then calculated the Spearman rank correlation $\left(=r_{\mathrm{S}}\right)$ between the observed and the predicted rankings of the groups. These two test statistics were combined using the formula $r_{\mathrm{s}} P_{\mathrm{c}}$, where $P_{\mathrm{c}}$ is the complement $(1-p)$ of the $P$ value from the ANOva. Critical values for the $r_{\mathrm{S}} P_{\mathrm{c}}$ statistic are presented in Rice and Gaines (1994a).

Data which were not normalized using logarithmic transformation were analyzed using KruskalWallis one-way anova. The resulting $P$-value was used along with a Spearman rank correlation statistic in an $\mathrm{OH}$ analysis as described above for the parametric tests.

\section{RESULTS}

Summary data for percent mandibular fat and age, by collection year, are presented in Tables 1-3. Not surprisingly, non-reproductive females clearly tend to be younger and have lower fat levels. While in each case there is a general increase in fat and maternal age associated with larger reproductive effort as defined by Williams (1979); there are also obvious exceptions to these trends.

The jaw fat data from 1986 and 1987 were normally distributed without transformation; however, age data for 1986 and 1987 required logarithmic transformation to achieve normality. ANOVA of these four data sets showed that the means were significantly different (all $P$ values $<0.001$ ). Spearman rank correlations were 0.514 for 1986 jaw fat, 0.829 for 1986 age, 0.857 for 1987 jaw fat and 0.857 for 1987 age. The $r_{\mathrm{S}} P_{\mathrm{c}}$ values (same order) were $0.59(P=0.02), 0.83(P=0.002), 0.851$ $(P=0.005)$ and $0.851(P=0.005)$.

Neither of the 1988 data sets were normally distributed and neither logarithmic transformations nor other standard transformations (e.g square, square root, inverse) improved this distribution. Therefore, we used a Kruskal-Wallis test for each of these data sets and the results showed that there were significant differences among the means of the groups within each set (both $P<0.001$ ). The Spearman rank correlation was 0.817 for both the 1988 age and 1988 jaw fat data. The corresponding $r_{\mathrm{S}} P_{c}$ values were both 0.82 (both $P=0.001$ ).

Because we were concerned that our consistently significant results might be the result of bias due to the inclusion of non-reproductive females, we repeated the analyses with that group excluded (Table 4). The results of this additional test were similar for the tests of the effect of female age, but the analyses of jaw fat for 1986 and 1987 showed no significant effect. We note that the 1988 data set, where jaw fat does appear important, has both a larger sample size, which may have improved the Kruskal-Wallis test, and more reproductive classes, which may have improved the Spearman rank correlation test.

\section{DISCUSSION}

Here we demonstrated that in three of three cases, maternal fat and maternal age levels increase in the 
Table 4. Statistics resulting from parametric (1986 and 1987 data) and non-parametric Kruskal-Wallis (1988 data) ANOVA, Spearman rank correlations, and ordered heterogeneity tests (see text for test descriptions), excluding females without offspring

\begin{tabular}{llcc}
\hline & ANOVA & Spearman rank & $r_{\mathrm{s}} P_{\mathrm{c}}$ \\
\hline 1986 & & & \\
$\quad$ Jaw fat & $\mathrm{F}_{4,71}=0.191(0.942)$ & 0.10 & $<0.01(>0.10)$ \\
Age & $\mathrm{F}_{4,71}=5.505(0.001)$ & 0.70 & $0.70(0.02)$ \\
1987 & & & $0.0(>0.10)$ \\
$\quad$ Jaw fat & $\mathrm{F}_{5,82}=0.308(0.907)$ & 0.00 & $0.75(0.01)$ \\
Age & $\mathrm{F}_{5,82}=2.760(0.024)$ & 0.77 & \\
1988 & & & $0.62(0.005)$ \\
Jaw fat & $\mathrm{KW}_{8}=10.56(0.162)$ & 0.74 & $0.27(0.06)$ \\
Age & $\mathrm{KW}_{8}=55.36(0.001)$ & 0.27 & \\
\hline
\end{tabular}

$P$ values are in parentheses following test statistic values.

direction predicted by Williams (1979). When the analyses are limited to females actually carrying young, the results are the same in one of three of the maternal fat tests, and in all three of the maternal age tests. This is a much more specific result than simply finding that two different offspring sex ratio groups differ in the manner predicted by Trivers and Willard (1973), as has been done in some other studies (e.g. Kucera 1991).

In contrast to the methodology and general results reported here, DeGayner and Jordon (1987) used logistic regression and reported an opposite age bias: older does with twins were more likely to have daughters while younger does tended to have sons. Unfortunately, their data are not presented in a way that permits us to re-analyze it using $\mathrm{OH}$. However, they tested the Trivers and Willard model using only three offspring number/sex classes: two daughters; one son, one daughter; and two sons. If they had used the full range of number/sex classes their results may have been different.

DeGayner and Jordan (1987) considered that their results supported the Verme (1983) model; we question this support and other aspects of the model as well. For example, Verme explicitly suggested that a doe with unusually good reproductive resources is likely to achieve higher reproductive fitness by producing a daughter rather than a son. Data contradictory to this hypothesis are reported by Ozoga and Verme (1986a), who studied offspring sex ratio in seventy-three 33 month old does. Eighteen of these does had failed to reproduce in the previous year, and were significantly heavier at the beginning of their second potential reproductive season. They also had a significantly higher offspring sex ratio (i.e. more sons) in that second season than did the deer which had reproduced in their first adult year. This implies that, at least in some situations, female while-tailed deer in relatively good condition tend to produce sons, while those in poor condition tend towards daughters.

The two models also differ in assumptions of patterns of parental investment according to offspring sex. Trivers and Willard (1973) and Williams (1979) assumed that the production of a son is more costly than the production of a daughter, but that a son can ultimately result in higher fitness returns. Verme (1983) assumed that because sons are so strongly influenced by conditions after termination of parental care, high levels of investment are unlikely to be profitable. However, as newborns, male twins have a higher mass than do female twins, and males also grow faster during their first month of life (Verme 1963). Verme (1989) also reported that at both parturition and in the following autumn, single sons weighed more than single daughters, twin males weighed more than twin daughters and that the sons in mixed sex litters weighed more than the daughters. This suggests that mothers do in fact invest more resources in sons than in daughters, contrary to Verme (1983).

Verme's model also depends on the assumptions that older females are likely to be of higher rank, that female offspring tend to give birth near their mothers and later inherit their mother's birthing ground and that quality fawning sites are limited. 
These assumptions are primarily based on Ozoga et al. (1982), a study of a high density penned herd designed to test the effects of "extreme crowding". Ozoga et al. (1982) presented relevant data from only a single matriarchy followed for 2 years and composed of one "older" female and her two daughters. Fawning sites, which were considered "high quality" by Ozoga et al. if they were isolated from other deer and appeared to be disturbed less often, may have been limited because the pen was so crowded. Relevance to wild populations is unclear, particularly as to whether good fawning sites are limited in wild populations, or if high quality fawning sites result in increased reproductive success. Also, conflicting evidence is available as well; Ozoga and Verme (1986b) reported that 3 year old daughters "normally" went to new ranges distant from that of their mothers.

The validity of these two models of optimal offspring sex ratio are based on how well they identify important selective forces and predict the impact of the forces on individual animals. Either or both models may be well founded but fail to accurately predict maternal behavior because of the impact of other selective or non-selective forces. For example, in the absence of a plausible mechanism, or at least evidence that in some taxa the phenomenon does exist, speculation about optimal sex ratio biasing may appear to be mere armchair biology. However, DeGayner and Jordan (1987) summarized research that demonstrates a possible mechanism for such biasing in Odocoileus, in which female control of the timing of copulation appears to influence offspring sex ratio. A similar mechanism has been demonstrated in other mammals (Hendricks \& McClintock 1990; Huck et al. 1990). Also, the existence of offspring sex ratio biasing supporting the Trivers and Willard model has been clearly established in other mammals such as red deer (Cervus elephus; Clutton-Brock et al. 1984, 1987), opossums (Didelphis marsupialis; Austad \& Sunquist 1986), golden hamsters (Mesocricetus auratus; Huck et al. 1986; Pratt et al. 1989) and domestic swine (Sus scrofa; Meikle et al. 1993), among others.

\section{ACKNOWLEDGEMENTS}

We greatly appreciate the generosity of the Michigan Department of Natural Resources, particularly
Ed Langenau, Harry Hill and Paul Friedrich, for sharing these data with us. We also thank Steven Gaines and John Warner for statistical assistance. Pamela Harpel-Burke recognized the value of this data set and brought it to our attention.

\section{REFERENCES}

Austad S. \& Sunquist M. (1986) Sex-ratio manipulation in the common opossum. Nature, 324, 58-60.

Clutton-Brock T. H. (1987) Sexual selection in the Cervidae. In: Biology and Management of the Cervidae (ed. C. M. Wemmer), pp. 110-122. Smithsonian Institution Press, Washington D.C.

Clutton-Brock T. H., Aidon S. D. \& Guinness F. E. (1984) Maternal dominance, breeding success and birth sex ratios in red deer. Nature, 308, 358-360.

Cuutton-Brock T. H., Aldon S. D. \& Guinness F. E. (1986) Great expectations: Dominance, breeding success and offspring sex ratios on red deer. Animal Bebavior, 34, 460-471.

DeGayner E. J. \& Jordan P. A. (1987) Skewed sex ratios in white-tailed deer: Evidence and evolutionary speculations. In: Biology and Management of the Cervidae (ed. C. M. Wemmer), pp. 178-188. Smithsonian Institution Press, Washington D.C.

Frank S. A. (1990) Sex allocation theory for birds and mammals. Annual Review of Ecology and Systematics, 21, 13-55.

Hendricks C. \& McClintock M. K. (1990) Timing of insemination is correlated with the secondary sex ratio of Norway rats. Physiology and Bebavior 48, 625632.

Huck U. W., Labov J. B. \& Lisk R. D (1986) Food restricting young hamsters (Mesocricetus auratus) affects offspring sex ratio and growth of subsequent offspring. Biology of Reproduction 35, 592-598.

Huck U. W., Seger J. \& Lisk R. D. (1990) Litter sex ratios in the golden hamster vary with the time of mating and litter size and are not binomially distributed. Bebavioral Ecology and Sociobiology 26, 99109.

KIR KPATRICK R. L. (1980) Physiological indices in wildlife management. In: Wildlife Tecbniques Manual (ed. S. D. Schemnitz), pp. 99-112. The Wildlife Society, Bethesda.

KuCERA T. E. (1991) Adaptive variation in sex ratios of offspring in nutritionally stressed mule deer. Journal of Mammalogy, 72, 745-749.

Leberg P., Smith M. H. \& Brisbin I. L. Jr (1991) Influence of sex, habitat, and genotype on the growth patterns of white-tailed deer. In: The Biology of Deer 
(ed. R. D. Brown), pp. 343-350. Springer-Verlag, New York.

Meikle D. B., Drickamer L. C., Vassey S. H., Rosenthal T. L. \& Fitzgerald K. S. (1993) Maternal dominance and secondary sex ratio in domestic swine. Animal Behavior 46, 79-85.

McCullough D. R. (1979) The George Reserve Deer Herd. University of Michigan Press, Ann Arbor.

Ozoga J. J. \& Verme L. J. (1986a) Initial and subsequent maternal success of white-tailed deer. Journal of Wildlife Management 50, 122-124.

Ozogn J. J. \& Verme L. J. (1986b) Relation of maternal age to fawn-rearing success in white-tailed deer. Journal of Wildlife Management 50, 480-486.

Ozoga J. J., Verme L. J. \& Bienz C. S. (1982) Parturition behavior and territoriality in white-tailed deer: Impact on neonatal mortality. Journal of Wildlife Management $46,1-11$.

Pratt N. C., Huck U. W. \& Lisk R. D. (1989) Do pregnant hamsters react to stress by producing fewer males? Animal Behavior 37, 155-157.

RICE W. R. \& GAINES S. D. (1994a) Extended nondirectional heterogeneity tests to evaluate simply ordered alternative hypotheses. Proceedings of the National Academy of Sciences USA, 91, 225-226.

Rice W. R. \& Gaines S. D. (1994b) The orderheterogeneity family of test. Biometrics 50, 746752.

Robinette W. L., Baer C. H., Pillmore R. E. \& Knittle C. E. (1973) Effects of nutritional change on captive mule deer. Journal of Wildlife Management 37, 312326.

SAuter P. R. (1984) Physical characteristics. In: White- tailed Deer: Ecology and Management (ed. L. K. Halls), pp. 73-90. Stackpole Books, Harrisburg.

Trivers R. L. \& W WLLARd D. E. (1973) Natural selection of parental ability to vary the sex ratio of offspring. Science, 179, 90-92.

VERME L. J. (1963) Effects of nutrition on growth of white-tailed deer fawns. In: Transactions of the 28th North American Wildlife and Natural Resources Conference (ed. J. B. Trefethen), pp. 431-443. American Wildlife Institute, Washington DC.

VeRME L. J. (1965) Reproductive studies on penned white-tailed deer. Joumal of Wildlife Management, 29, 74-79.

VERME L. J. (1969) Reproductive patterns of white-tailed deer related to nutritional plane. Journal of Wildlife Management, 33, 881-887.

Verme L. J. (1983) Sex ratio variation in Odocoileus: A critical review. Journal of Wildlife Management, 47, 573-582.

Verme L. J. (1985) Progeny sex ratio relationship in deer: Theoretical vs observed. Joumal of Wildlife Management, 49, 134-136.

VERME L. J. (1989) Maternal investment in white-tailed deer. Joumal of Mammalogy, 70, 438-442.

Verme L. J. \& U Urey D. E. (1984) Physiology and nurtrition. In: White-tailed Deer: Ecology and Management (ed. L. K. Halls), pp. 91-118. Stackploe Books, Harrisburg.

W ILKINSON L. (1990) Systat: The system for statistics. Systat, Inc., Evanston.

Williams G. C. (1979) The question of adaptive sex ratio in outcrossed vertebrates. Proceedings of the Royal Society of London Series B, 205, 567-580. 